\title{
Atomic cobalt anchored on covalent triazine frameworks with ultra-high performance towards oxygen reduction reaction
}

\author{
Shanke Zhou ${ }^{1,2}$, Zhichang Xiao ${ }^{1,2}$, Qi Yang ${ }^{1,2}$, Xiaoxiong Huang ${ }^{1,2}$, Yue Niu ${ }^{1,2}$, Yingjie $\mathrm{Ma}^{1^{*}}$ and \\ Linjie $\mathrm{Zhi}^{12^{*}}$
}

\begin{abstract}
Single cobalt atom is promising non-precious metal catalyst instead of $\mathrm{Pt}$ in the oxygen reduction reaction (ORR). However, it is still a great challenge to develop a costeffective, ultrastable and efficent single-atom cobalt catalyst for ORR, requiring efficient fabrication strategies and robust support to stabilize the single cobalt atom. Here, we prepared a highly active and stable atomically isolated cobalt catalyst via covalent triazine framework (CTF) support with Ketjen Black (KB) hybridization in scale. The prepared single Co catalyst (Co-CTF/KB) possesses high metal loading over $4 \mathrm{wt} \%$ and shows superior ORR performance with a half-wave potential $\left(E_{1 / 2}\right)$ of $0.830 \mathrm{~V}$ and a limiting current density of $6.14 \mathrm{~mA} \mathrm{~cm}^{-2}$ as well as high tolerance of methanol in an alkaline medium, which outperforms commercial $\mathrm{Pt} / \mathrm{C}$ and most non-precious-metal catalysts reported to date. Benefiting from strong stabilization of Co atoms on CTF, Co-CTF/ KB shows outstanding stability with only $5 \mathrm{mV}$ negative shifts after 10,000 cycles. Moreover, it also displays high catalytic activity for oxygen evolution reaction (OER), suggesting it is an efficient ORR/OER bifunctional catalyst. The present work provides a facile strategy for preparing single-atom catalysts in bulk quantity and contributes to development of catalysts for electrochemical conversion and storage devices.
\end{abstract}

Keywords: single-atom cobalt, non-precious metal catalysts, oxygen reduction reaction (ORR), covalent triazine framework (CTF) support, cost-effective scalable preparation

\section{INTRODUCTION}

The increasing energy crisis and rising environmental concerns call for the urgent development of renewable energy technologies, such as fuel cells and metal-air bat- teries [1-3]. Benefitting from high energy density and environment-friendly features, fuel cells and metal-air batteries are promising candidates for next generation of energy conversion and storage devices. However, their efficiencies strongly depend on the sluggish kinetics of oxygen reduction reaction (ORR) at the cathode [4,5]. To date, Pt-based materials are the most effective and available commercial ORR catalysts, but severely unavoidable disadvantages, such as high cost, serious deficiency, limited durability and fast deactivation by $\mathrm{CO}$, impede their scalable applications in practice [6-15]. Consequently, it has been the foremost topic of this field that exploring high-performance, durable, and earth-abundant nonprecious ORR electrocatalysts over the past few years [1618]. Among all the reported non-precious metal catalysts, including transition metal sulfides/oxides [19], nitrides [20], carbon materials [9], and perovskites [21], transition metal-coordinating nitrogen-doped carbon single-atom catalysts (SACs) (M-N-C, M = Fe or Co) have emerged as the most promising alternatives to Pt for ORR [22-26], because of their superior electrocatalytic activity, stability and low-cost scalable synthesis. In SACs, the smallest metal particles, i.e., single atoms, are distributed on the surface of support material, which are beneficial to boost their catalytic activities with the maximized atom utilization [27-31]. Both Fe-N-C and Co-N-C SACs exhibit high ORR activity, but Fe-N-C SACs always promote decomposition of $\mathrm{H}_{2} \mathrm{O}_{2}$ to produce hydroxyl and hydroperoxyl radical species, which will induce an deteriorated activity along with their decomposition of the active sites, membranes and carbon supports [32,33]. In contrast, Co$\mathrm{N}-\mathrm{C}$ SACs do not suffer from this problem and thus are

${ }^{1}$ CAS Key Laboratory of Nanosystem and Hierarchical Fabrication, CAS Center for Excellence in Nanoscience, National Center for Nanoscience and Technology, Beijing 100190, China

${ }^{2}$ University of Chinese Academy of Sciences, Beijing 100049, China

*Corresponding authors (emails: mayj@nanoctr.cn (Ma Y); zhilj@nanoctr.cn (Zhi L)) 
more promising durable ORR catalysts. As isolated metal atoms tend to aggregate during the preparation and catalytic process due to their high surface energy, the stability and ORR activity of Co-N-C SACs are mostly determined by the supports, which can anchor and expose the isolated active metal atoms to prevent them from aggregating, and modulate their morphology and electronic structures to boost their ORR activity. Therefore, to improve the ORR activity of isolated cobalt atoms, several $\mathrm{N}$-doped carbon supports $(\mathrm{N}-\mathrm{C})$ for cobalt SACs have been fabricated, such as hollow $\mathrm{N}$-doped carbon spheres prepared by $\mathrm{SiO}_{2}$ template-assisted pyrolysis of cobalt porphyrines [34,35], hierarchically porous $\mathrm{N}$ doped carbons fabricated by template-assisted pyrolysis of cobalt salts and small molecules [36,37], N-doped carbons derived from pyrolysis of metal-organic frameworks (MOFs) [33,38], N-doped carbon nanofibers synthesized by pyrolysis of nanofibers consisting of cobalt salts and carbon and nitrogen sources [32], and porphyrinic triazine-based frameworks prepared by trimerization of cobalt cyanoporphrine monomers [39]. With these supports, impressive improvement of ORR activity has been achieved, but such pyrolysis under high temperature usually leads to aggregation of unstable metallic compounds enclosed in carbon shells or inhomogeneous distribution of single metal atoms [33]. Thus, it is highly desirable to develop suitable supports with well-defined sites to anchor single cobalt atoms under moderate temperature, affording SACs with homogeneous distribution of atomically isolated cobalt in bulk quantity.

Recently, covalent triazine frameworks (CTFs) obtained from the trimerization of aromatic nitriles have emerged as suitable novel platforms for the synthesis of electrocatalysts [40-43] because of the following merits: 1) CTFs possess abundant pyridinic nitrogen atoms with lone pairs of electrons, which can efficiently bond with single metal atoms $[44,45]$; 2) CTFs feature porous structure with uniform nano pores, which are ideal sites to anchor single atoms and thus benefit exposing the active sites; 3 ) The covalently bonded framework of CTFs endows them with strong mechanical property, which might contribute to the stability of SACs; 4) CTFs synthesized by the ionothermal methods possess good electrical conductivity because partial graphitization will inevitably occur during the synthesis process [46]. Nevertheless, the role of CTFs in supporting single cobalt atoms towards ORR has not been explored, although they have worked as catalysts or support material for various applications, such as separation and storage of gases, energy storage, photocatalysis and heterogeneous catalysis $[46,47]$.
Herein, we prepared highly reactive and stable isolated single cobalt atoms supported by covalent triazine frameworks with Ketjen Black (KB) hybridization (Co-CTF/ $\mathrm{KB})$ for ORR. The as-fabricated $\mathrm{Co}-\mathrm{CTF} / \mathrm{KB}$ features conductive networks, unique porous structures, and high specific surface area as well as the abundance of atomically dispersed highly active Co-N-C sites. Consequently, Co-CTF/KB exhibits superior ORR activity with an onset potential of $0.940 \mathrm{~V}$, a half-wave potential of $0.830 \mathrm{~V}$, a high limiting current density of $6.14 \mathrm{~mA} \mathrm{~cm}^{-2}$ and a low Tafel slope of $65 \mathrm{mV} \mathrm{dec}^{-1}$, which outperform commercial $\mathrm{Pt} / \mathrm{C}$ and most non-precious-metal catalysts reported to date. Furthermore, Co-CTF/KB shows long-term stability with little ORR polarization curve shift after 10,000 cycles. In addition, it also displays superior methanol tolerance with negligible current change in the presence of $3.0 \mathrm{~mol} \mathrm{~L}^{-1}$ methanol. This work presents large-scale preparation of a low-cost, ultrastable and efficient singleatom Co electrocatalyst with high metal loading content for ORR.

\section{EXPERIMENTAL SECTION}

\section{Sample preparation}

Synthesis of CTF: $0.5 \mathrm{~g}$ of 2,6-dicyanopyridine and $5.28 \mathrm{~g}$ of $\mathrm{ZnCl}_{2}$ were mixed in a glove box $(99.99 \%$ argon with $0.1 \mathrm{ppm}$ water). The mixture was transferred into a glass ampoule pipe and the pipe was evacuated, sealed, heated at the rate of $5^{\circ} \mathrm{C} \mathrm{min}^{-1}$ and maintained at $400^{\circ} \mathrm{C}$ for $21 \mathrm{~h}$. The resulting powder was washed with $0.1 \mathrm{~mol} \mathrm{~L}^{-1} \mathrm{HCl}$, water and tetrahydrofuran in sequence, and then dried under vacuum at $80^{\circ} \mathrm{C}$ for $12 \mathrm{~h}$, giving a dark powder.

Synthesis of CTF/KB: $0.5 \mathrm{~g}$ of 2,6-dicyanopyridine, $0.5 \mathrm{~g}$ of KB EC600JD and $5.28 \mathrm{~g}$ of $\mathrm{ZnCl}_{2}$ were mixed in a glove box (99.99\% argon with $0.1 \mathrm{ppm}$ water). The mixture was transferred into a glass ampoule pipe and the pipe was evacuated, sealed, heated at the rate of $5^{\circ} \mathrm{C} \mathrm{min}^{-1}$ and maintained at $400^{\circ} \mathrm{C}$ for $21 \mathrm{~h}$. The resulting powder was washed with $0.1 \mathrm{~mol} \mathrm{~L}^{-1} \mathrm{HCl}$, water and tetrahydrofuran in sequence, and then dried under vacuum at $80^{\circ} \mathrm{C}$ for $12 \mathrm{~h}$, giving a dark powder.

Synthesis of Co-CTF/KB: $100 \mathrm{mg}$ of CTF/KB and $100 \mathrm{mg}$ of cobalt (II) acetate tetrahydrate were put into $50 \mathrm{~mL}$ of methanol, respectively, and treated with sonication for $1 \mathrm{~h}$. Then, cobalt (II) acetate tetrahydrate solution was injected to the suspension of $\mathrm{CTF} / \mathrm{KB}$ in methanol and kept at $60^{\circ} \mathrm{C}$ for $4 \mathrm{~h}$. The as-obtained product was centrifuged and washed with methanol thrice. Finally, the Co-CTF/KB was obtained after drying in an oven at $80^{\circ} \mathrm{C}$ for $12 \mathrm{~h}$. 


\section{Sample characterization}

The X-ray diffraction (XRD) was tested by X-ray diffraction (Rigaku D/max-2500B2+/PCX system). The transmission electron microscopy (TEM) images and high-resolution images were observed with Field-emission transmission electron microscopy (FE-TEM, Tecnai G2 F20 U-TWIN). Scanning transmission electron microscopy (STEM) and elemental mapping images were collected from high-angle annular dark-field STEM (HAADF-STEM). The HAADF-STEM images were carried out in an aberration-corrected JEOL ARM-200F system equipped with a cold field emission gun and an ASCOR probe corrector at $60 \mathrm{kV}$. The cobalt concentrations of the samples were conducted on the inductively coupled plasma atomic emission spectroscopy (ICP-AES). The X-ray photoelectron spectroscopy (XPS) experiments were performed on an ESCALAB250Xi system with a monochromatic $\mathrm{Al} \mathrm{Ka} \mathrm{X}$-ray source. Nitrogen adsorption and desorption isotherms were determined by nitrogen physisorption at $77 \mathrm{~K}$ on a Micrometritics ASAP 2020 analyzer. The samples were degassed under vacuum at $150^{\circ} \mathrm{C}$ for $10 \mathrm{~h}\left(10^{-5}\right.$ bar $)$ before analysis. The specific surface area (SBET) was calculated by the BrunauerEmmet-Teller (BET) approach. Pore size distribution data was calculated based on the density functional theory (DFT) model.

\section{Electrochemical measurements}

All the electrochemical measurements were carried out in a conventional three-electrode system using the CHI760E electrochemical station (Shanghai Chenhua Instrument Factory, China), in which saturated calomel electrode (SCE, $1.015 v s$. reversible hydrogen electrode (RHE) in $\left.0.1 \mathrm{~mol} \mathrm{~L}^{-1} \mathrm{KOH}\right)$ and platinum net $\left(0.1 \mathrm{~cm}^{2}\right)$ were regarded as the reference electrode and the counter electrode, respectively, with $0.1 \mathrm{~mol} \mathrm{~L}^{-1} \mathrm{KOH}$ aqueous solution as the electrolyte. Rotating disk electrode (RDE) and rotating ring-disk electrode (RRDE) tests were both detected by American Pine Instruments device. Five milligram of catalyst was ultrasonically dispersed in $1 \mathrm{~mL}$ ethanol for about $30 \mathrm{~min}$, and then $50 \mu \mathrm{L}$ of $0.5 \mathrm{wt} \%$ Nafion solution was added. The mixture was sonicated for $1 \mathrm{~h}$ to form a homogeneous catalyst ink. Then, $10 \mu \mathrm{L}$ of the as-prepared catalyst ink was dropped on the RDE, giving loading of $0.255 \mathrm{mg} \mathrm{cm}^{-2}$. The commercially available carbon-supported $\mathrm{Pt} / \mathrm{C}$ electrode was prepared according to the above procedure with loading of $\sim 0.255 \mathrm{mg} \mathrm{cm}^{-2}$. Before testing, $\mathrm{O}_{2}$ flow was carried out through the electrolyte in the cell for about $30 \mathrm{~min}$ to achieve the $\mathrm{O}_{2}$-saturated solution. The cyclic voltammetry
$(\mathrm{CV})$ tests were measured in $\mathrm{O}_{2}$-saturated $0.1 \mathrm{~mol} \mathrm{~L}^{-1}$ $\mathrm{KOH}$ solution with a scan rate of $50 \mathrm{mV} \mathrm{s}^{-1}$. RDE/RRDE tests were conducted in $\mathrm{O}_{2}$-saturated $0.1 \mathrm{~mol} \mathrm{~L}^{-1} \mathrm{KOH}$ at different rotation rates with a sweep rate of $10 \mathrm{mV} \mathrm{s}^{-1}$ at room temperate. The electron transfer number $(n)$ and hydrogen peroxide yield $\left(\mathrm{H}_{2} \mathrm{O}_{2} \%\right)$ were calculated by the following equations:

$n=4 \times \frac{I_{\mathrm{d}}}{I_{\mathrm{d}}+I_{\mathrm{r}} / N}$,

$\mathrm{H}_{2} \mathrm{O}_{2}(\%)=200 \times \frac{I_{\mathrm{r}} / N}{I_{\mathrm{d}}+I_{\mathrm{r}} / N}$,

where $I_{\mathrm{d}}$ is the disk current, $I_{\mathrm{r}}$ is the ring current, and $N=$ 0.37 is the current collection efficiency of the Pt ring [9].

The polarization curves were collected at various disk rotation rates of 400, 625, 900,1225, 1600, 2025 and 2500 rpm, respectively, for the RDE examination. Thus, the number of electrons transferred $(n)$ was calculated using Koutecky-Levich equations to analyze the kinetic parameters on the basis of the following equations:

$\frac{1}{J}=\frac{1}{J_{\mathrm{L}}}+\frac{1}{J_{\mathrm{K}}}=\frac{1}{B \omega^{1 / 2}}+\frac{1}{J_{\mathrm{K}}}$,

$B=0.62 n F C_{0} D_{0}^{2 / 3} \vartheta^{-1 / 6}$,

where $J$ is the measured current density, and $J_{\mathrm{K}}$ and $J_{\mathrm{L}}$ are the kinetic-limiting current densities and diffusion-limiting current densities, respectively. Where, $\omega$ is the angular velocity. $n$ is the number of electrons transferred per oxygen molecule. $F$ is the Faraday constant $\left(96,500 \mathrm{C} \mathrm{mol}^{-1}\right) \cdot C_{0}$ is the bulk concentration of $\mathrm{O}_{2}$ in $0.1 \mathrm{~mol} \mathrm{~L}^{-1} \mathrm{KOH}\left(1.2 \times 10^{-3} \mathrm{~mol} \mathrm{~L}^{-1}\right) . D$ is the diffusion coefficient of $\mathrm{O}_{2}$ in $0.1 \mathrm{~mol} \mathrm{~L}^{-1} \mathrm{KOH}\left(1.9 \times 10^{-5} \mathrm{~cm}^{2} \mathrm{~s}^{-1}\right) . v$ is the kinematic viscosity of the electrolyte $\left(0.01 \mathrm{~cm}^{2} \mathrm{~s}^{-1}\right)$.

\section{RUSULTS AND DISCUSSION}

As an ideal support for single-atom $\mathrm{Co}$, the proposed CTF should have binding sites and well-defined pores to anchor and accommodate single cobalt atoms. Thus, 2,6dicyanopyridine was chosen as the monomer to prepare the target CTF as it provides extra binding sites for Co atoms besides triazine frameworks. And KB was hybridized with the target CTF to increase the conductivity of this composite. As shown in Fig. 1, CTF/KB was obtained by in situ polymerization of 2,6-dicyanopyridine in-molten $\mathrm{ZnCl}_{2}$ containing $\mathrm{KB}$, and then was functionalized with Co atoms within a solution of cobalt(II) acetate in methanol through an impregnation strategy, obtaining $\mathrm{Co}-\mathrm{CTF} / \mathrm{KB}$.

The morphology of Co-CTF/KB and CTF/KB was examined by TEM. The TEM images of KB, CTF and CTF/ 


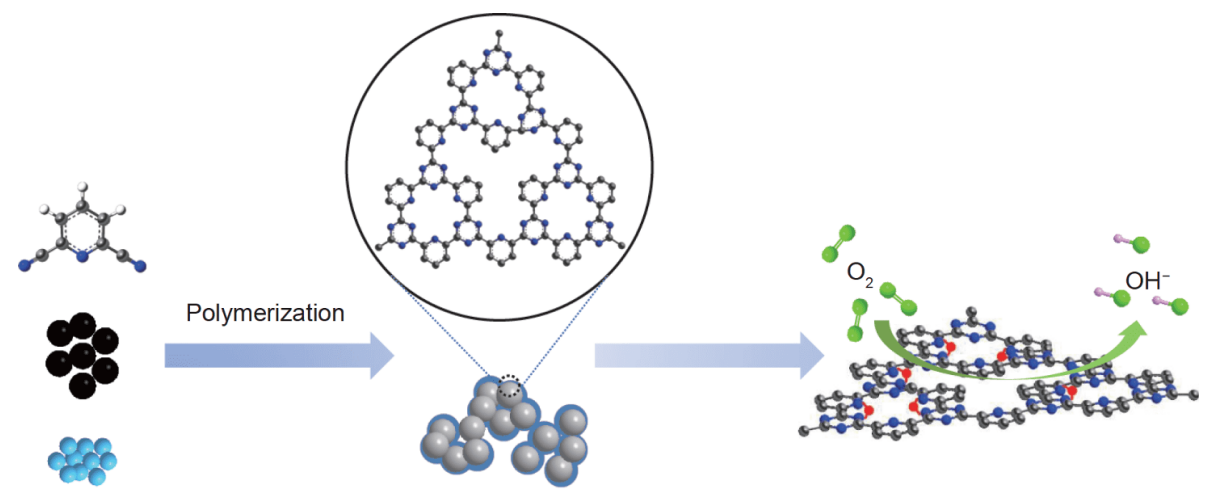

Figure 1 Schematic diagram of synthesis and structure of Co-CTF/KB and its application in ORR (blue: N, red: Co and black: C).

$\mathrm{KB}$ (Fig. S1) show no large CTF bulks in $\mathrm{CTF} / \mathrm{KB}$, implying that $\mathrm{CTF}$ is well mixed with $\mathrm{KB}$ during the polymerization. High-resolution TEM of Co-CTF/KB reveals that no metal nanoparticles $(>1 \mathrm{~nm})$ aggregate on Co$\mathrm{CTF} / \mathrm{KB}$ (Fig. 2a). The existing form and atomic distribution of Co atoms were also verified via HAADFSTEM with sub-angstrom resolution, which is a powerful tool for identifying individual metal atoms. As shown in Fig. 2c, numerous evenly distributed white bright dots at atomic scale are observed on the surface of Co-CTF/KB (highlighted by red circles), while no clusters and nanoparticles of Co species are observed, suggesting that the Co is atomically dispersed on the support. And the corresponding energy-dispersive X-ray spectroscopy (EDX) elemental mappings show that $\mathrm{Co}$ and $\mathrm{N}$ atoms are uniformly distributed over the entire architecture of Co$\mathrm{CTF} / \mathrm{KB}$ as well (Fig. 2b).

Furthermore, the XRD spectrum of Co-CTF/KB only shows one broad carbon peak at $\sim 24^{\circ}$ and no other peaks of metallic Co and/or Co compounds can be observed (Fig. S2), meaning that there is only atomic cobalt on $\mathrm{CTF} / \mathrm{KB}$ support, which is consistent with the HR-TEM result. The ICP-AES analysis shows that Co-CTF/KB possesses a bulk Co content of $\sim 4.16 \mathrm{wt} \%$ (Table S1). All these results strongly suggest high dispersion of single cobalt atoms in the CTF/KB.

To investigate the cobalt coordination in $\mathrm{Co}-\mathrm{CTF} / \mathrm{KB}$, $\mathrm{CTF} / \mathrm{KB}$ was chosen as the reference. The wide-range XPS analysis reveals that there are $\mathrm{C}, \mathrm{N}$ and $\mathrm{O}$ in both $\mathrm{CTF} / \mathrm{KB}$ and $\mathrm{Co}-\mathrm{CTF} / \mathrm{KB}$, but only $\mathrm{Co}-\mathrm{CTF} / \mathrm{KB}$ contains Co (Fig. S3). Moreover, the nitrogen species and chemical environments of nitrogen in $\mathrm{CTF} / \mathrm{KB}$ and $\mathrm{Co}-\mathrm{CTF} / \mathrm{KB}$ were explored by high-resolution $\mathrm{C} 1 \mathrm{~s}$ and $\mathrm{N} 1 \mathrm{~s}$ analysis. In the C 1s XPS spectrum of Co-CTF/KB (Fig. S4), there are two peaks at $\sim 284.7$ and $285.7 \mathrm{eV}$ in $\mathrm{C} 1 \mathrm{~s}$ region, which can be assigned to carbon atoms neighbored with carbon and nitrogen atoms, respectively, revealing that nitrogen atoms are anchored within a carbon backbone. As shown in Fig. S5, four peaks at 398.7, 399.4, 400.7 and $402.0 \mathrm{eV}$ corresponding to pyridinic $\mathrm{N}$, pyrrolic $\mathrm{N}$, graphitic $\mathrm{N}$, oxidized $\mathrm{N}$, respectively, can be observed in the high-resolution $\mathrm{N}$ 1s spectra of CTF/KB [48]. In contrast, there is a new peak around $399.6 \mathrm{eV}$ in the $\mathrm{N} 1$ s spectrum of Co-CTF/KB (Fig. 2d) with $1 \mathrm{eV}$ upshift compared with the pristine pyridinic $\mathrm{N}(\sim 398.7 \mathrm{eV})$ [49], which could be ascribed to the energy of pyridinic $\mathrm{N}$ that binds cobalt in Co- $\mathrm{N}_{x}$ as the literature reported [50], but not that of pyrrolic $\mathrm{N}$ that binds cobalt because if $\mathrm{Co}$ is bound to pyrrolic $\mathrm{N}$, like in porphyrins, the peak will appear at a lower binding energy of $\sim 398.5 \mathrm{eV}$ [51]. Moreover, theoretical calculation by DFT also predicted that the position of $C o-\mathrm{N}_{x}$ peak should be in the range of 399.3-400.9 eV [52]. The formation of Co- $\mathrm{N}_{x}$ was further confirmed by the Co 2p XPS analysis (Fig. S6). In the Co $2 p$ XPS spectrum (Fig. S6), there are two distinct peaks at $\sim 782.1$ and $780.5 \mathrm{eV}$, which can be ascribed to cobalt in Co- $\mathrm{N}_{x}$ and $\mathrm{Co}-\mathrm{C}_{x}-\mathrm{N}_{y}$, respectively [53]. The above analysis indicates that Co atoms are anchored by nitrogen atoms of CTF in $\mathrm{Co}-\mathrm{CTF} / \mathrm{KB}$ and atomically dispersed on the nitrogen-doped framework of CTF, giving Co-N-C moieties. Additionally, Co-CTF/KB also possesses high BET specific surface area of $734.2 \mathrm{~m}^{2} \mathrm{~g}^{-1}$ and large pore volume of $0.71 \mathrm{~cm}^{3} \mathrm{~g}^{-1}$ (Fig. S7 and Table S2), which will benefit the exposure of rich active sites to oxygen and mass-transport of oxygen and electrolyte.

The electrocatalytic activities of $\mathrm{Co}-\mathrm{CTF} / \mathrm{KB}$ for ORR were investigated by $\mathrm{CV}$ and linear sweep voltammetric (LSV) measurements on an $\mathrm{RDE}$ in $\mathrm{O}_{2}$-saturated $0.1 \mathrm{~mol} \mathrm{~L}^{-1} \mathrm{KOH}$ solution at $20^{\circ} \mathrm{C}$. As shown in Fig. 3a, distinct cathodic peaks are observed for both $\mathrm{Co}-\mathrm{CTF} / \mathrm{KB}$ and $\mathrm{CTF} / \mathrm{KB}$ in the $\mathrm{O}_{2}$-saturated electrolyte. However, the ORR peak current density for Co-CTF/KB $(0.820 \mathrm{~V})$ is 
a

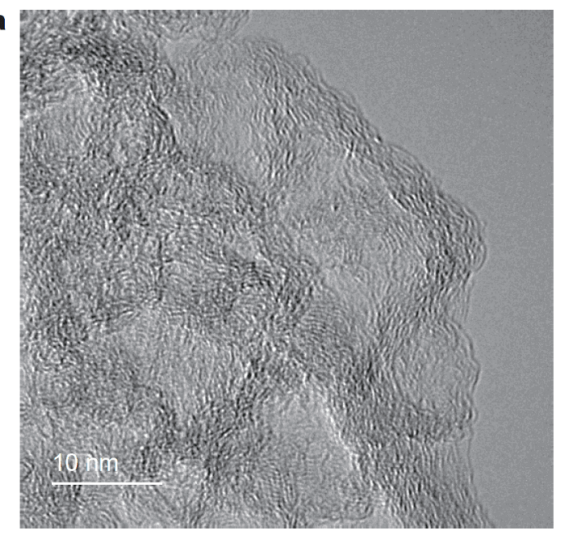

C

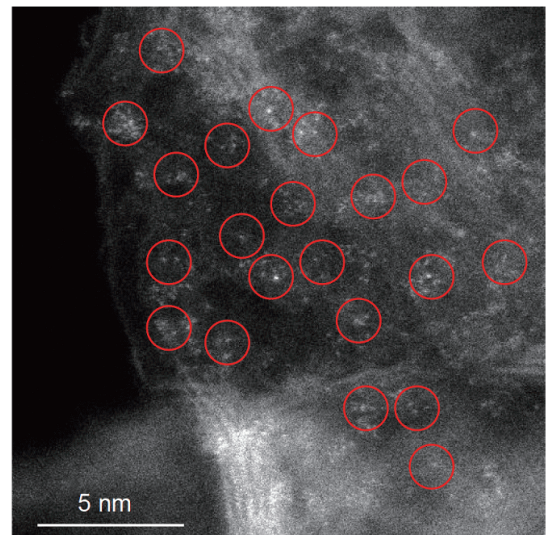

b
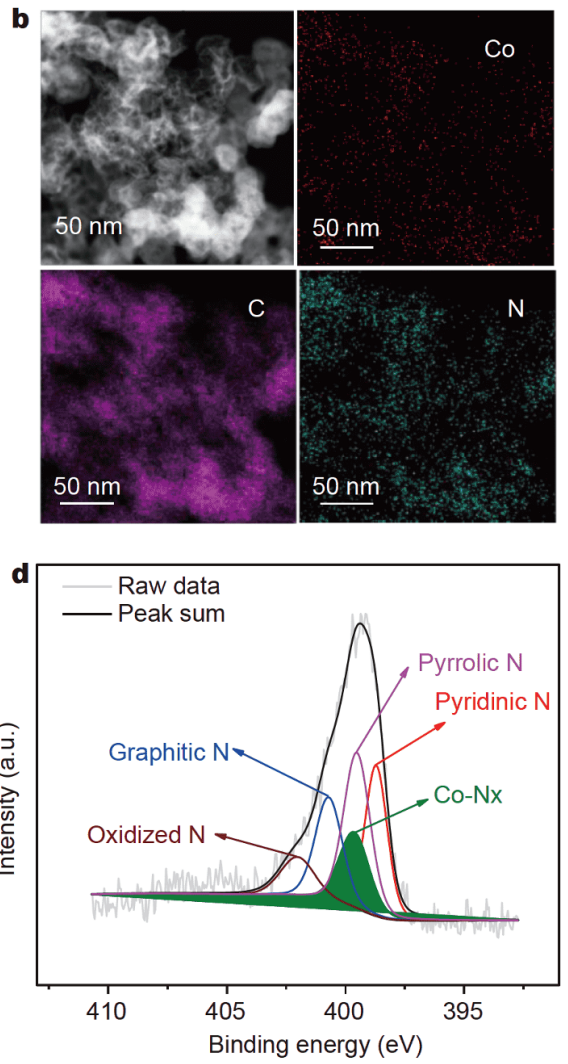

Figure 2 (a) High-resolution transmission electron microscopy (HR-TEM) images of Co-CTF/KB. (b)HAADF-STEM image and the corresponding element mapping of Co-CTF/KB: Co (red), C (purple), N (cyan). (c) HAADF-STEM image of Co-CTF/KB (isolated bright dots marked with red circles are cobalt atoms) and (d) N 1s XPS spectrum of Co-CTF/KB.

obviously more positive than that of CTF/KB $(0.680 \mathrm{~V})$. The LSV further reveals that Co-CTF/KB has an outstanding ORR activity in terms of the limiting current density and half-wave potential $\left(E_{1 / 2}\right)$. As shown in Fig. 3b, the limiting current density of $\mathrm{Co}-\mathrm{CTF} / \mathrm{KB}$ is $6.14 \mathrm{~mA} \mathrm{~cm}^{-2}$, higher than that of CTF/KB $\left(4.5 \mathrm{~mA} \mathrm{~cm}^{-2}\right)$ and $\mathrm{Pt} / \mathrm{C}\left(5.6 \mathrm{~mA} \mathrm{~cm}^{-2}\right)$, and the $E_{1 / 2}$ for $\mathrm{Co}-\mathrm{CTF} / \mathrm{KB}$ $(0.830 \mathrm{~V})$ is more positive than that of $\mathrm{CTF} / \mathrm{KB}(0.70 \mathrm{~V})$ and $\mathrm{Pt} / \mathrm{C}(0.810 \mathrm{~V})$, indicating that $\mathrm{Co}-\mathrm{N}-\mathrm{C}$ species give rise to much better ORR activity compared with $\mathrm{N}-\mathrm{C}$ sites and consequently highlighting the critical role of metal center (Co-N-C) in ORR catalytic activity. Moreover, Co$\mathrm{CTF} / \mathrm{KB}$ shows the lowest Tafel slope of $65 \mathrm{mV} \mathrm{dec}^{-1}$ compared with $\mathrm{CTF} / \mathrm{KB} \quad\left(71 \mathrm{mV} \mathrm{dec}^{-1}\right)$ and $\mathrm{Pt} / \mathrm{C}$ (75 mV dec ${ }^{-1}$ ), suggesting that Co-CTF/KB is an excellent ORR catalyst with superior kinetics. The distinct Tafel slope values for $\mathrm{Co}-\mathrm{CTF} / \mathrm{KB}$ and $\mathrm{CTF} / \mathrm{KB}$ further reveal that the rate limiting step are improved after incorporating Co-N-C active sites. Theoretical calculation has also proven that singlely dispersed cobalt sites could significantly increase the hydrogenation of $\mathrm{OH}^{\star}$ species in the process of ORR [35].

The ORR kinetics of Co-CTF/KB was also evaluated by an RDE system at different rotation rates (400-2500 rpm) in $0.1 \mathrm{~mol} \mathrm{~L}^{-1} \mathrm{KOH}$ (Fig. 3d). Based on the KouteckyLevich $(\mathrm{K}-\mathrm{L})$ equation, the electron transfer number $(n)$ of $\mathrm{Co}-\mathrm{CTF} / \mathrm{KB}$ calculated from the diffusion-controlled region to the kinetics-controlled region $(0.2$ to $0.75 \mathrm{~V})$ is approximately 4 (Fig. 3e), while the electron transfer number of $\mathrm{CTF} / \mathrm{KB}$ is smaller than 3.7 (Fig. S8). The electron transfer number $(n)$ and peroxide percentage of $\mathrm{CTF} / \mathrm{KB}$ and $\mathrm{Co}-\mathrm{CTF} / \mathrm{KB}$ were also evaluated by the RRDE (Fig. 3f). The RRDE analysis indicates that the $n$ value of $\mathrm{Co}-\mathrm{CTF} / \mathrm{KB}$ is $3.92-4.0$ in the whole potential range, which is well consistent with the result of $\mathrm{RDE}$. Simultaneously, the $\mathrm{H}_{2} \mathrm{O}_{2}$ yield of Co-CTF/KB in alkaline condition is below $10 \%$ at all potentials, meaning that $\mathrm{Co}$ $\mathrm{CTF} / \mathrm{KB}$ possesses high selectivity towards 4-electron pathway in the ORR process. All these above results confirm that the catalytic process at the Co-CTF/KB 

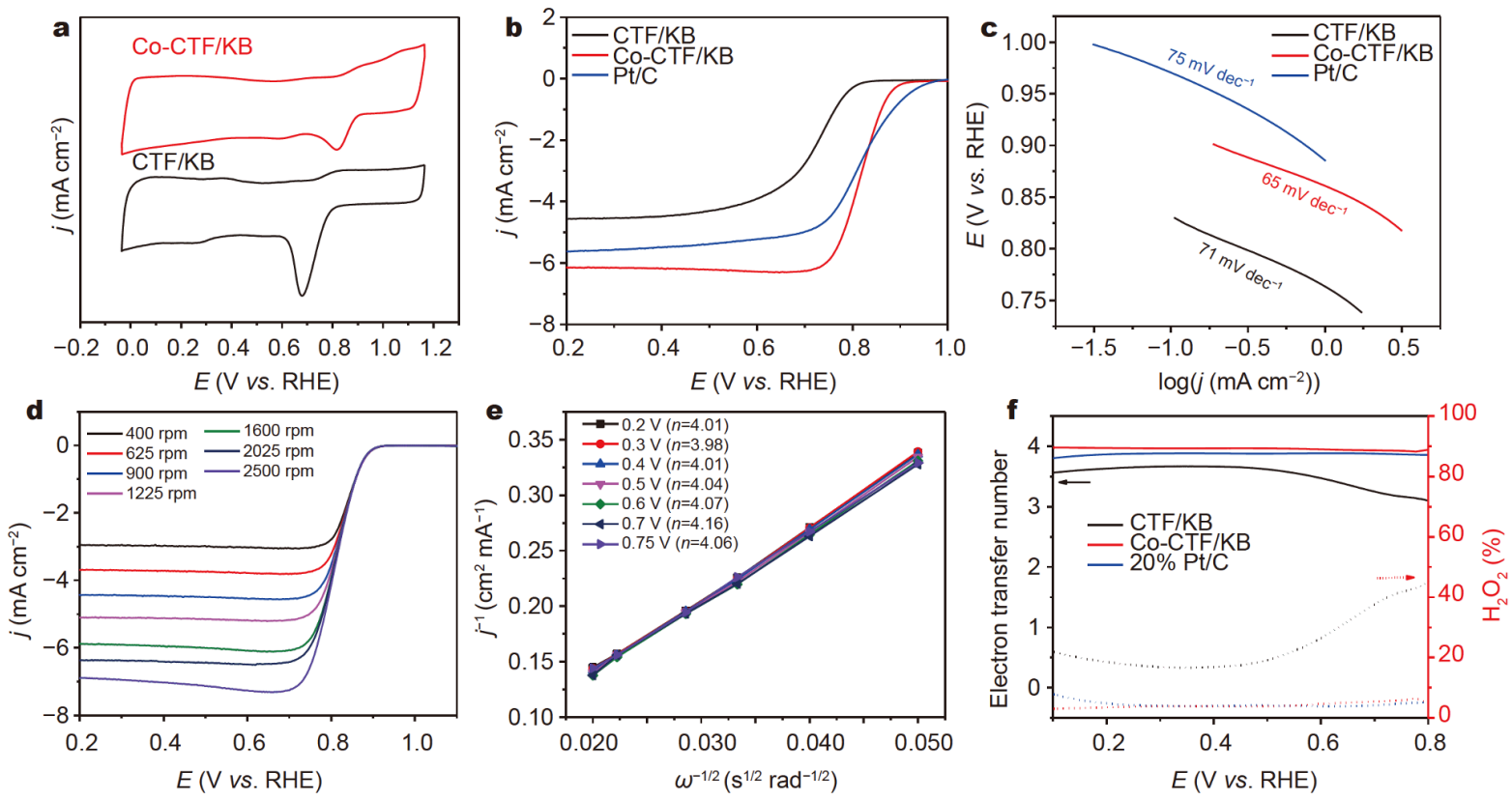

Figure 3 (a) $\mathrm{CV}$ curves of $\mathrm{CTF} / \mathrm{KB}$ and $\mathrm{Co}-\mathrm{CTF} / \mathrm{KB}$ at a scan rate of $50 \mathrm{mV} \mathrm{s}^{-1}$. (b) LSV curves and (c) the corresponding Tafel plots of Pt/C, CTF/ $\mathrm{KB}$ and $\mathrm{Co}-\mathrm{CTF} / \mathrm{KB}$ at a scan rate of $10 \mathrm{mV} \mathrm{s}^{-1}$ with $1600 \mathrm{rpm}$. (d) LSV curves at different rotating rates and (e) the corresponding K-L plots and electron transfer numbers of Co-CTF/KB. (f) The electron transfer numbers of ORR and $\mathrm{H}_{2} \mathrm{O}_{2}$ production on the ring electrode during ORR reaction for $\mathrm{CTF} / \mathrm{KB}, \mathrm{Co}-\mathrm{CTF} / \mathrm{KB}$ and $\mathrm{Pt} / \mathrm{C}$, respectively. The catalyst loading was about $0.255 \mathrm{mg} \mathrm{cm}^{-2}$ for all tests.

electrode undergoes a 4-electron ORR pathway in alkaline medium, implying an excellent ORR catalytic efficiency.

To identify the distinguished performance between Co$\mathrm{CTF} / \mathrm{KB}$ and $\mathrm{CTF} / \mathrm{KB}$, their electrochemical surface areas (ECSAs) were investigated, which is an important standard parameter to evaluate the ORR activity. According to the $\mathrm{CV}$ plots in Ar-saturated $0.1 \mathrm{~mol} \mathrm{~L}^{-1} \mathrm{KOH}$, ECSAs of the two electrodes were calculated by electrochemical double-layer capacitances (EDLCs) between 0.964 and $1.166 \mathrm{~V}$ (versus RHE) at various scan rates (Fig. S9). Obviously, the Co-CTF/KB exhibits the $C_{\mathrm{dl}}$ (electrical double-layer capacitance) of $12.1 \mathrm{mF} \mathrm{cm}^{-2}$, which is about $29 \%$ higher than that of CTF/KB $\left(9.4 \mathrm{mF} \mathrm{cm}^{-2}\right)$, demonstrating that $\mathrm{Co}-\mathrm{CTF} / \mathrm{KB}$ possesses much more exposed active sites than $\mathrm{CTF} / \mathrm{KB}$ and thus contributing to its superior ORR activity (Fig. 4a).

The long-term stability of Co-CTF/KB was evaluated by $\mathrm{CV}$ between 0.5 and $1.0 \mathrm{~V}$ at a scan rate of $50 \mathrm{mV} \mathrm{s}^{-1}$ in $\mathrm{O}_{2}$-saturated $0.1 \mathrm{~mol} \mathrm{~L}^{-1} \mathrm{KOH}$. After 10,000 continuous cycles, Co-CTF/KB retains a similar LSV curve to the initial one with $\sim 5 \mathrm{mV}$ negative shift for $E_{1 / 2}$ (Fig. $4 \mathrm{~b}$ ) and only $3 \mathrm{mV} \mathrm{dec}{ }^{-1}$ negative shift for Tafel slope (Fig. S10), which are lower than most reported values of non-precious metal catalysts [35], showing the outstanding stability in alkaline media. Furthermore, in order to examine the fuel crossover effect, the chronoamperometric response $(i-t)$ of $\mathrm{Co}-\mathrm{CTF} / \mathrm{KB}$ and commercial $20 \% \mathrm{Pt} / \mathrm{C}$ were compared in $0.1 \mathrm{~mol} \mathrm{~L}^{-1} \mathrm{KOH}+3 \mathrm{~mol} \mathrm{~L}^{-1}$ methanol solutions (Fig. 4c). There is no obvious oscillation in the current density on Co-CTF/KB after injecting $3 \mathrm{~mol} \mathrm{~L}^{-1}$ methanol into the electrolyzing solution, while the current density of $20 \% \mathrm{Pt} / \mathrm{C}$ catalyst decreases about $20 \%$ under the same condition, suggesting that $\mathrm{Co}-\mathrm{CTF} / \mathrm{KB}$ has outstanding tolerance to methanol crossover. The above results highlight the remarkable ORR electrocatalytic performance of $\mathrm{Co}-\mathrm{CTF} / \mathrm{KB}$ that outperforms commercial $\mathrm{Pt} / \mathrm{C}$ and most reported single-atom electrocatalysts (Fig. S11 and Table S3). The $\mathrm{SCN}^{-}$poison experiment was also carried out to further confirm the role of Co- $\mathrm{N}_{x}$ in ORR (Fig. S12). After the introduction of $\mathrm{SCN}^{-}$, the $E_{1 / 2}$ and diffusion-limited current density of $\mathrm{Co}-\mathrm{CTF} / \mathrm{KB}$ is found to be decreased, further manifesting that the Co- $\mathrm{N}_{x}$ is the active site for ORR.

Besides ORR activity, Co-CTF/KB also shows electrocatalytic oxygen evolution reaction (OER) activity, which was investigated in $\mathrm{O}_{2}$-saturated $0.1 \mathrm{~mol} \mathrm{~L}^{-1} \mathrm{KOH}$ at 1600 $\mathrm{rpm}$. Co-CTF/KB displays lower onset potential and much higher current density as compared with $20 \% \mathrm{Pt} / \mathrm{C}$ and $\mathrm{RuO}_{2}$ (Fig. 4d), exhibiting that Co-CTF/KB possesses superior OER activity to $\mathrm{Pt} / \mathrm{C}$. The overall oxygen elec- 

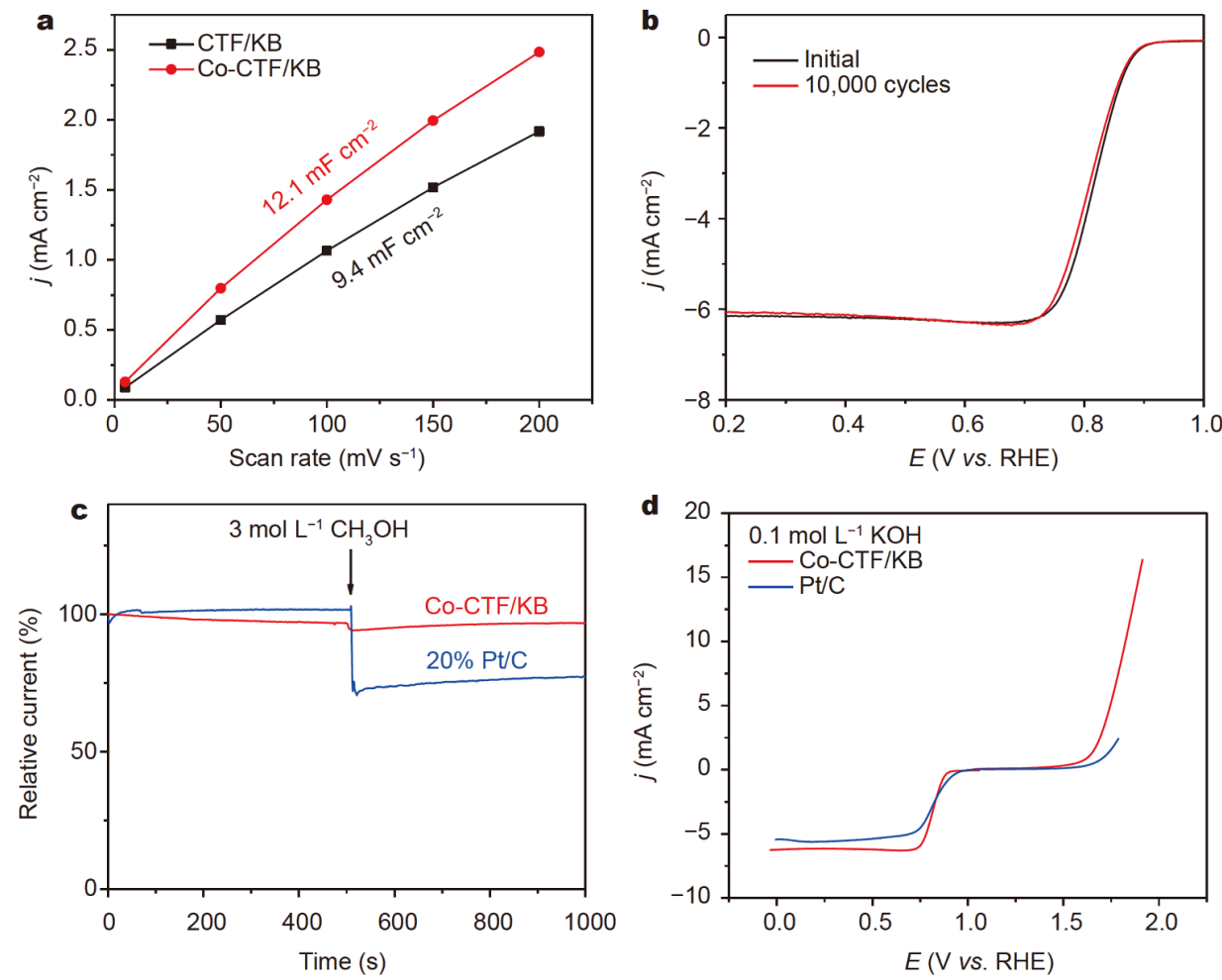

Figure 4 (a) The electrical double-layer capacitance at $1.1 \mathrm{~V}$ with various scan rates for CTF/KB and Co-CTF/KB, respectively. (b) LSV curves of Co$\mathrm{CTF} / \mathrm{KB}$ before and after 10,000 cycles, respectively. (c) The methanol tolerance of Co-CTF/KB and $\mathrm{Pt} / \mathrm{C}$ by chronoamperometric response $(i-t)$ in $\mathrm{O}_{2}-$ saturated $0.1 \mathrm{~mol} \mathrm{~L}^{-1} \mathrm{KOH}$ solution with and without methanol. (d) LSV curves of different catalysts $\left(10 \mathrm{mV} \mathrm{s}^{-1}\right)$, showing the bifunctional ORR/OER catalytic activity.

trode performance was evaluated by $\Delta E\left(E_{\mathrm{OER}}-E_{\mathrm{ORR}}\right)$ between the OER potential at $10.0 \mathrm{~mA} \mathrm{~cm}{ }^{-2}$ and the ORR potential at $E_{1 / 2}$. Co-CTF/KB has a low potential difference around $0.95 \mathrm{~V}$, validating that $\mathrm{Co}-\mathrm{CTF} / \mathrm{KB}$ possesses good ORR/OER bifunctional activities, which arise from its unique features, including abundant atomically dispersed highly active Co-N-C sites, conductive networks, unique hierarchical porous structure, and high specific surface area.

\section{CONCULSIONS}

In conclusion, we presented scalable preparation of a cost-effective, highly active and stable single-atom cobalt catalyst supported by CTF hybridized with KB. Featured by the defined nitrogen active sites and porous stucture along with high specific surface area, Co atoms can be strongly anchored with nitrogen atoms and well dispersed on the CTF/KB skeleton. Consequently, Co-CTF/KB exhibits excellent activities for ORR in alkaline media. It also shows extraordinary long-term stability and excellent methanol tolerance. In addition, $\mathrm{Co}-\mathrm{CTF} / \mathrm{KB}$ also exhibits good OER catalytic activity, suggesting that $\mathrm{Co}-\mathrm{CTF} / \mathrm{KB}$ can work as a bifunctional catalyst for ORR and OER. This work opens up an avenue for developing high-efficiency and stable noble-metal-free single-atom cobalt catalysts for reversible energy conversion and storage devices.

Received 29 November 2020; accepted 6 January 2021; published online 24 March 2021

1 Winter M, Brodd RJ. What are batteries, fuel cells, and supercapacitors? Chem Rev, 2004, 104: 4245-4270

2 Bashyam R, Zelenay P. A class of non-precious metal composite catalysts for fuel cells. Nature, 2006, 443: 63-66

3 Debe MK. Electrocatalyst approaches and challenges for automotive fuel cells. Nature, 2012, 486: 43-51

4 Wu G, More KL, Johnston CM, et al. High-performance electrocatalysts for oxygen reduction derived from polyaniline, iron, and cobalt. Science, 2011, 332: 443-447

5 Gewirth AA, Thorum MS. Electroreduction of dioxygen for fuelcell applications: materials and challenges. Inorg Chem, 2010, 49: 3557-3566

6 Choe JE, You JM, Yun M, et al. Manganese dioxide/reduced graphene oxide with poly(3,4-ethylenedioxythiophene) for improved electrocatalytic oxygen reduction reaction. J Nanosci Nanotechnol, 2015, 15: 5684-5690

7 Cui L, Lv G, He X. Enhanced oxygen reduction performance by 
novel pyridine substituent groups of iron (II) phthalocyanine with graphene composite. J Power Sources, 2015, 282: 9-18

8 Chang HY, Lee KY. Characteristics of nitrogen-doped carbon films grown by sputtering as potential cathode catalysts for oxygen reduction reaction. Jpn J Appl Phys, 2015, 54: 085801

9 Zhang J, Zhao Z, Xia Z, et al. A metal-free bifunctional electrocatalyst for oxygen reduction and oxygen evolution reactions. Nat Nanotech, 2015, 10: 444-452

10 Liang $\mathrm{Y}, \mathrm{Li} \mathrm{Y}$, Wang $\mathrm{H}$, et al. $\mathrm{Co}_{3} \mathrm{O}_{4}$ nanocrystals on graphene as a synergistic catalyst for oxygen reduction reaction. Nat Mater, 2011, 10: $780-786$

11 Lv Y, Yang L, Cao D. Nitrogen and fluorine-codoped porous carbons as efficient metal-free electrocatalysts for oxygen reduction reaction in fuel cells. ACS Appl Mater Interfaces, 2017, 9: 3285932867

12 Nie Y, Li L, Wei Z. Recent advancements in Pt and Pt-free catalysts for oxygen reduction reaction. Chem Soc Rev, 2015, 44: 2168-2201

13 Sa YJ, Seo DJ, Woo J, et al. A general approach to preferential formation of active $\mathrm{Fe}-\mathrm{N}_{x}$ sites in $\mathrm{Fe}-\mathrm{N} / \mathrm{C}$ electrocatalysts for efficient oxygen reduction reaction. J Am Chem Soc, 2016, 138: 15046-15056

14 Chen C, Kang Y, Huo Z, et al. Highly crystalline multimetallic nanoframes with three-dimensional electrocatalytic surfaces. Science, 2014, 343: 1339-1343

15 Liu H, Nosheen F, Wang X. Noble metal alloy complex nanostructures: controllable synthesis and their electrochemical property. Chem Soc Rev, 2015, 44: 3056-3078

16 Chen Z, Higgins D, Yu A, et al. A review on non-precious metal electrocatalysts for PEM fuel cells. Energy Environ Sci, 2011, 4: 3167-3192

17 Han J, Sa YJ, Shim Y, et al. Coordination chemistry of [Co(acac $\left.)_{2}\right]$ with $\mathrm{N}$-doped graphene: Implications for oxygen reduction reaction reactivity of organometallic $\mathrm{Co}-\mathrm{O}_{4}-\mathrm{N}$ species. Angew Chem Int Ed, 2015, 54: 12622-12626

18 Masa J, Xia W, Sinev I, et al. Eine Stickstoff-dotierte Kohlenstoffmatrix mit eingeschlossenen $\mathrm{Mn}_{x} \mathrm{O}_{y} / \mathrm{NC}-$ und $\mathrm{Co}_{x} \mathrm{O}_{y} / \mathrm{NC}-\mathrm{Na}-$ nopartikeln für leistungsfähige bifunktionale Sauerstoffelektroden. Angew Chem, 2014, 126: 8648-8652

19 Li G, Wang X, Fu J, et al. Pomegranate-inspired design of highly active and durable bifunctional electrocatalysts for rechargeable metal-air batteries. Angew Chem Int Ed, 2016, 55: 4977-4982

20 Chen $\mathrm{P}, \mathrm{Xu} \mathrm{K}$, Fang $\mathrm{Z}$, et al. Metallic $\mathrm{Co}_{4} \mathrm{~N}$ porous nanowire arrays activated by surface oxidation as electrocatalysts for the oxygen evolution reaction. Angew Chem, 2015, 127: 14923-14927

21 Petrie JR, Cooper VR, Freeland JW, et al. Enhanced bifunctional oxygen catalysis in strained $\mathrm{LaNiO}_{3}$ perovskites. J Am Chem Soc, 2016, 138: 2488-2491

22 Wang $\mathrm{Y}$, Kong A, Chen X, et al. Efficient oxygen electroreduction: Hierarchical porous $\mathrm{Fe}-\mathrm{N}$-doped hollow carbon nanoshells. ACS Catal, 2015, 5: 3887-3893

23 Yang L, Cheng D, Xu H, et al. Unveiling the high-activity origin of single-atom iron catalysts for oxygen reduction reaction. Proc Natl Acad Sci USA, 2018, 115: 6626-6631

24 Shen H, Gracia-Espino E, Ma J, et al. Synergistic effects between atomically dispersed $\mathrm{Fe}-\mathrm{N}-\mathrm{C}$ and $\mathrm{C}-\mathrm{S}-\mathrm{C}$ for the oxygen reduction reaction in acidic media. Angew Chem, 2017, 129: 13988-13992 Shen $\mathrm{H}$, Gracia-Espino E, Ma J, et al. Atomically $\mathrm{FeN}_{2}$ moieties dispersed on mesoporous carbon: A new atomic catalyst for efficient oxygen reduction catalysis. Nano Energy, 2017, 35: 9-16

26 Shang L, Yu H, Huang X, et al. Well-dispersed ZIF-derived Co,N- co-doped carbon nanoframes through mesoporous-silica-protected calcination as efficient oxygen reduction electrocatalysts. Adv Mater, 2016, 28: 1668-1674

27 Yang XF, Wang A, Qiao B, et al. Single-atom catalysts: a new frontier in heterogeneous catalysis. Acc Chem Res, 2013, 46: 17401748

28 Liu P, Zhao Y, Qin R, et al. Photochemical route for synthesizing atomically dispersed palladium catalysts. Science, 2016, 352: 797800

29 Thomas JM. Tens of thousands of atoms replaced by one. Nature, 2015, 525: 325-326

30 Zhang W, Zheng W. Single atom excels as the smallest functional material. Adv Funct Mater, 2016, 26: 2988-2993

31 Cui X, Xiao J, Wu Y, et al. A graphene composite material with single cobalt active sites: A highly efficient counter electrode for dye-sensitized solar cells. Angew Chem Int Ed, 2016, 55: 67086712

32 Cheng Q, Yang L, Zou L, et al. Single cobalt atom and N codoped carbon nanofibers as highly durable electrocatalyst for oxygen reduction reaction. ACS Catal, 2017, 7: 6864-6871

33 Wang XX, Cullen DA, Pan YT, et al. Nitrogen-coordinated single cobalt atom catalysts for oxygen reduction in proton exchange membrane fuel cells. Adv Mater, 2018, 30: 1706758

34 Wu F, Pan C, He CT, et al. Single-atom Co- $\mathrm{N}_{4}$ electrocatalyst enabling four-electron oxygen reduction with enhanced hydrogen peroxide tolerance for selective sensing. J Am Chem Soc, 2020, 142: 16861-16867

35 Han Y, Wang YG, Chen W, et al. Hollow N-doped carbon spheres with isolated cobalt single atomic sites: Superior electrocatalysts for oxygen reduction. J Am Chem Soc, 2017, 139: 17269-17272

36 Sun T, Zhao S, Chen W, et al. Single-atomic cobalt sites embedded in hierarchically ordered porous nitrogen-doped carbon as a superior bifunctional electrocatalyst. Proc Natl Acad Sci USA, 2018, 115: 12692-12697

37 Zhu C, Shi Q, Xu BZ, et al. Hierarchically porous $\mathrm{M}-\mathrm{N}-\mathrm{C}(\mathrm{M}=\mathrm{Co}$ and $\mathrm{Fe}$ ) single-atom electrocatalysts with robust $\mathrm{MN}_{x}$ active moieties enable enhanced ORR performance. Adv Energy Mater, 2018, 8: 1801956

38 Yin $\mathrm{P}, \mathrm{Yao} \mathrm{T}, \mathrm{Wu} \mathrm{Y}$, et al. Single cobalt atoms with precise Ncoordination as superior oxygen reduction reaction catalysts. Angew Chem, 2016, 128: 10958-10963

39 Yi JD, Xu R, Chai GL, et al. Cobalt single-atoms anchored on porphyrinic triazine-based frameworks as bifunctional electrocatalysts for oxygen reduction and hydrogen evolution reactions. J Mater Chem A, 2019, 7: 1252-1259

40 Kuhn P, Antonietti M, Thomas A. Porous, covalent triazine-based frameworks prepared by ionothermal synthesis. Angew Chem Int Ed, 2008, 47: 3450-3453

41 Hao L, Zhang S, Liu R, et al. Bottom-up construction of triazinebased frameworks as metal-free electrocatalysts for oxygen reduction reaction. Adv Mater, 2015, 27: 3190-3195

42 Puthiaraj P, Lee YR, Zhang S, et al. Triazine-based covalent organic polymers: design, synthesis and applications in heterogeneous catalysis. J Mater Chem A, 2016, 4: 16288-16311

43 Ren S, Bojdys MJ, Dawson R, et al. Porous, fluorescent, covalent triazine-based frameworks via room-temperature and microwaveassisted synthesis. Adv Mater, 2012, 24: 2357-2361

44 Kamai R, Kamiya K, Hashimoto K, et al. Oxygen-tolerant electrodes with platinum-loaded covalent triazine frameworks for the hydrogen oxidation reaction. Angew Chem, 2016, 128: 13378- 
13382

45 Kamiya K, Kamai R, Hashimoto K, et al. Platinum-modified covalent triazine frameworks hybridized with carbon nanoparticles as methanol-tolerant oxygen reduction electrocatalysts. Nat Commun, 2014, 5: 1-6

46 Liu M, Guo L, Jin S, et al. Covalent triazine frameworks: synthesis and applications. J Mater Chem A, 2019, 7: 5153-5172

47 Krishnaraj C, Jena HS, Leus $\mathrm{K}$, et al. Covalent triazine frameworks-a sustainable perspective. Green Chem, 2020, 22: 10381071

48 Yang L, Shi L, Wang D, et al. Single-atom cobalt electrocatalysts for foldable solid-state Zn-air battery. Nano Energy, 2018, 50: 691698

49 Tang C, Wang B, Wang HF, et al. Defect engineering toward atomic Co- $\mathrm{N}_{x}-\mathrm{C}$ in hierarchical graphene for rechargeable flexible solid Zn-air batteries. Adv Mater, 2017, 29: 1703185

50 Artyushkova K, Serov A, Rojas-Carbonell S, et al. Chemistry of multitudinous active sites for oxygen reduction reaction in transition metal-nitrogen-carbon electrocatalysts. J Phys Chem C, 2015, 119: 25917-25928

51 Kothandaraman R, Nallathambi V, Artyushkova K, et al. Nonprecious oxygen reduction catalysts prepared by high-pressure pyrolysis for low-temperature fuel cells. Appl Catal B-Environ, 2009, 92: 209-216

52 Artyushkova K, Kiefer B, Halevi B, et al. Density functional theory calculations of XPS binding energy shift for nitrogen-containing graphene-like structures. Chem Commun, 2013, 49: 2539-2541

53 Qian Y, Liu Z, Zhang H, et al. Active site structures in nitrogendoped carbon-supported cobalt catalysts for the oxygen reduction reaction. ACS Appl Mater Interfaces, 2016, 8: 32875-32886

Acknowledgements This work was supported by the Ministry of Science and Technology of China (2012CB933403), the National Natural Science Foundation of China (51425302 and 51302045), and the Chinese Academy of Sciences.

Author contributions Zhi L and Ma Y conceived and supervised the project and designed the experiments; Zhou S performed the synthesis, characterization, electrochemical and electrocatalytic measurement; Xiao Z, Yang Q, Huang X and Niu Y assisted in characterization and electrocatalytic measurements; Zhi L, Ma Y and Zhou S wrote the manuscript and revised it. All authors contributed to the general discussion.

Conflict of interest The authors declare no conflict of interest.

Supplementary information Experimental details and supporting data are available in the online version of the paper.

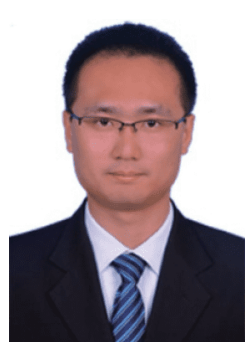

Shanke Zhou is currently pursuing his $\mathrm{PhD}$ at the National Center for Nanoscience and Technolgy under the supervision of Prof. Linjie Zhi. He completed his Master's degree from Dalian University of Technology. His research is currently focusing on the development of singleatom electrocatalysts for ORR and OER.

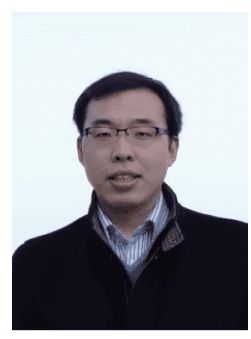

Yingjie Ma received his $\mathrm{PhD}$ in chemistry from Zhejiang University in 2013. Then, he joined Prof. Klaus Müllen's group at Max-Planck Institute for Polymer Research as postdoctor (2013-2016). Since the end of 2016, he has been an assistant researcher in the National Center for Nanoscience and Technology. His research interests focus on the synthesis of functional organic molecules and their applications in energy storage and catalysis.

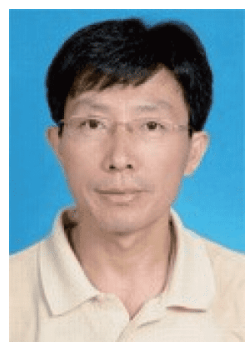

Linjie Zhi received his $\mathrm{PhD}$ in 2000 from the Institute of Coal Chemistry, Chinese Academy of Sciences. From 2003, he had worked with Prof. Klaus Müllen at Max-Planck Institute for Polymer Research for two years before assuming the position of project leader until the end of 2007 . Since early 2008, he has been a professor in the National Center for Nanoscience and Technology. His research interests focus on carbon-rich nanomaterials and their applications in energyrelated areas.

\section{具有高效氧还原反应催化活性的共轭三嗪骨架材 料负载的单原子钴催化剂}

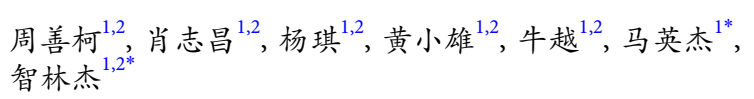

摘要 单原子钴是一种理想的代替铂催化氧还原反应 $(O R R)$ 的非 贵金属催化剂, 然而制备低成本、高稳定性且高效的此类催化剂 仍面临挑战. 这需要高效的制备策略以及强健的支撑材料以稳定 单原子钴. 因此, 我们提出了一种适于大量制备的三嗪骨架材料负 载的单原子钴 ORR 催化剂 $(\mathrm{Co}-\mathrm{CTF} / \mathrm{KB})$. 其单原子钴负载量达 $4 \mathrm{wt} \%$, 在碱性介质中 ORR催化性能超过商用 $\mathrm{Pt} / \mathrm{C}$ 和大部分已报道 的非贵金属催化剂: 半波电位 $\left(E_{1 / 2}\right)$ 达 $0.830 \mathrm{~V}$, 截止电流为 $6.14 \mathrm{~mA} \mathrm{~cm}^{-2}$, 且具有极高的甲醇耐受性. 得益于CTF对钴单原子 的强稳定性, Co-CTF/KB催化循环 10000 圈后, 电位偏移仅 $5 \mathrm{~mA}$, 展现出极好的循环稳定性. 此外, Co-CTF/KB还能催化析氧反应 (OER), 是一种高效、高稳定的ORR/OER双功能催化剂. 此工作为 规模化制备高质量的单原子催化剂提供了新思路. 